Check for updates

London, UK

Cite this as: BMJ 2020;370:m2909 http://dx.doi.org/10.1136/bmi.m2909 Published: 20 July 2020

\section{Covid-19: England could need another lockdown in winter, say government's chief advisers}

Adrian O’Dowd

England could require another national lockdown during the winter because of the prevalence of flu and other respiratory viruses alongside covid-19, the government's chief medical and scientific advisers have suggested.

Giving evidence to the House of Lords science and technology committee on 17 July, the government's chief scientific adviser Patrick Vallance and chief medical officer Chris Whitty underlined the long term impact of covid-19 by saying that measures such as self-isolation, social distancing, contact tracing, and face coverings could be needed into 2021 .

Vallance said, "Winter is going to be a very complex time, where most people who end up with the symptoms of covid-19 may have something else. So, there are going to be people potentially being isolated for reasons that are not covid-19.”

He warned that another lockdown in England was possible during winter, saying, “As you release measures, it's inevitable that as you get more contacts, you will see more cases. The critical question is measurement and detection as early as possible and understanding how to react. Come winter, the challenges will be much greater and there is a risk that this could need national measures as well.”

Whitty said social distancing measures were likely to be around for a long time, saying, "There are some things that we started right at the beginning, which have to continue for a prolonged period of time-washing hands, isolation, and household isolation.

“Then we've added things like contact tracing and face coverings. The reality is that distancing remains an important part of this mix. So, all of those need to continue for a long period of time. It's possible that in winter we may have to do some additional things," he said.

The committee asked the advisers if the scientific evidence was pointing towards a second wave of the virus later in the year.

Vallance said, "The modelling has suggested from the beginning that the risk of a second wave is high and there is a significant chance that it will come back in force and we need to be prepared for that.

"We are much better prepared in terms of our understanding of the measures that need to be in place to try and deal with it, but I think we should be alert."

When asked what assumptions were being made about the transmission of covid-19 in the winter months, Whitty said, “We can't be absolutely certain but, given that so many respiratory viruses are benefited by the winter, we have to assume that it'll be benefited by the winter.

“There is both a combined potential biological impact and there's definitely a combined practical impact because the NHS is under much more strain over the winter months and that's partly because of flu and other respiratory infections."

Whitty said there should be more capacity this year to expand the winter flu vaccination programme, and said it was possible that vaccination eligibility would be extended upwards and downwards from the current age limits. 